\title{
Materials as temporally specific phenomena: Specialization and compromise in bioplastics production
}

Journal of Material Culture 2018, Vol. 23(I) II4-130 (C) The Author(s) 2017 Reprints and permissions: sagepub.co.uk/journalsPermissions.nav DOI: I0.II77/|359|835|7725547 journals.sagepub.com/home/mcu

(S)AGE

\section{Damla Tonuk}

Gaziantep University, Turkey

\begin{abstract}
This article concerns itself with the 'materials' - matter, substance - of material culture. More specifically, it explores the making of bioplastics, by taking account of bioplastics' relationships with the products into which they are made. The author focuses on the processes of bioplastics' industrial production and manufacturing into bioplastic products, in and through which bioplastics come to be as they are in our daily lives, and as places where material-product relationships are formed. Her analysis of these processes shows that making of bioplastics is a specialization towards products by achieving compromises among the capacity of materials, conventions about the particular product and its production route, and various interests of the stakeholders involved. As such, she conceptualizes materials as temporally specific phenomena and aims to show that attending to material-product relationships points out new sets of relationships in the make-up of materiality and opens up new pathways of enquiry for material culture studies.
\end{abstract}

\section{Keywords}

bioplastics, industrial production, making materials, material-product relationships, materials

\section{Introduction}

This article focuses on materials - matter, substance - of materiality, in particular a group of materials categorized as 'bioplastics' that are currently and rapidly in the making. I explore how bioplastics have come to be as they are and are changing, and the processes involved. This obviously figures as an ambitious project, but my specific focus helps me to draw a perspective from which to explore these processes. I am particularly interested

\section{Corresponding author:}

Damla Tonuk, Gaziantep University, Gaziantep 27310, Turkey.

Email: damlatonuk@gmail.com 
in the relationship between bioplastics and the products into which they are made, since I acknowledge that there is, in the making of materials, almost an obligatory relationship between materials and products; we do not come across materials devoid of object forms in our daily lives. This obligatory relationship has been addressed in the special issue of the journal Archaeological Dialogues on materials:

It is the objects themselves that capture our attention, no longer the materials of which they are made. It is as though our material involvement begins only when the stucco has already hardened on the house front or the ink already dried on the page. (Ingold, 2007: 9)

In his article, Ingold frames the relationship between materials and products in tension, as products obscure and hinder our appreciation of materials, where 'materials appear to vanish, swallowed up by the very objects to which they have given birth' (p. 9). He suggests that we should look at a stone from the garden, as, according to him, only then can we apprehend the material bare of products and human involvement. However, Miller (2007) and Tilley (2007), in the same issue of the journal, question the cultural and artefactual nature of even a pebble picked from the garden and they point to its significance in a social and historical context. Miller (2007) even doubts whether plastic should be thought of separate from the mobile phone it is made into and the human involvement in this making as, for him, materials and objects they are made into are inseparable.

Despite a relationship between materials and products that might at first sight appear to be in tension, or as just the opposite, materials and products might be regarded as inseparable, Shove et al. (2007: 98) conceptualize the relationship between materials and products as 'co-constitutive'. Through their account of the Parkesine comb, Shove et al. exemplify how materials and products make each other. They realize, firstly, that to communicate the qualities of this new material - Parkesine - a product was needed. Secondly, the product - the comb - in return defined the valuable properties of Parkesine, as well as positioning Parkesine among other materials of which combs used to be made, such as tortoise shell or bone. Moreover, Shove et al. recognize that this relationship is dynamic and ongoing (p. 102). Parkesine has 'multiple co-existing incarnations' as other types of products, such as medallions, card cases or pens, thereby multiplying the qualities and identities of Parkesine. This also creates 'completely new terms of comparison, value and exchange' for the material as well as the product (p. 107) in that with each materialproduct combination new values and material taxonomies are produced and reproduced. The idea of 'co-constitution' allows me to grasp the fluid field of bioplastics, within dynamic and co-evolving relationships, both to subjects - different individuals, actors and environments as most studies on materials from within different disciplines explored (Banerjee and Miller, 2003; Bijker, 1995; Klein, 2009; Misa, 1995; Sheller, 2014), but also to objects and other materials (Shove et al., 2007).

To explore these relationships, I focus on production of materials; their industrial production and manufacturing into products, for I see these processes as places where the material can be observed devoid of a product form, as well as in relation to products. I hope to show that this product oriented story will open up new pathways for studies on materials as well as objects. I propose that there are some insights to be gained for the studies of materials (as well as objects) from attending to the differences as well as 
interrelations between materials and products, and that attending to the subtleties of material-product relationships might contribute to a deeper understanding of materiality within material culture studies and the social sciences more broadly.

\section{Bioplastics: An emergent and a fluid field}

Bioplastics are types of plastics, meaning they are particular molecular configurations of carbon atoms. The main features of these materials as well are organized around the lifestory of carbon: the source of carbon should come from living organisms, such as plants - making them biobased - and/or the carbon molecules should be able to breakdown to a format that living (micro-) organisms can digest - making them biodegradable. In this sense, bioplastics are similar to what Küchler (2011) calls 'materials by design'. Although her focus is mainly on smart materials, she observes that today's materials are engineered for specific use qualities, in that materials 'themselves (are) subject to design' (p. 126) in processes of invention 'that is the practice of iterative improvement, with the iterative process itself providing added value' (Küchler, 2015: 15; see also Barry, 2005, and Pinch and Bijker, 1984 for similar conceptualizations of invention). From within different disciplinary traditions, from cultural history to business history, from studies of science and technology to material culture, studies on materials - either elemental like metals such as aluminium (Schatzberg, 2003; Sheller, 2014) and steel (Misa, 1995) or extracted bodily fluids like milk (Orland, 2009), or compounds and designed materials like plastics (Meikle, 1997), such as PET (Hawkins, 2013), and Nylon (Handley, 1999) - have shown that materials come to be as they are through various iterative processes in and through relationships between subjects - individual actors and influential social, industrial or governmental groups (Misa, 1995; Sheller, 2014) - different disciplinary traditions, their material culture and practices (Klein, 2009), and infrastructures such as patenting organizations or electrical infrastructures (Akrich, 1992; Bijker, 1995). In addition to being alert to these iterative processes in the making of bioplastics, my specific focus means that I will pay attention to the mutually constitutive relationships between bioplastics and the products into which they are made.

It is important to note, however, that there is an ambiguity in the field in terms of the materials that are 'in' the category 'bioplastics' - hence the usage in the plural - as well as the producers and industries that are relevant. There are a growing number of different types of bioplastics, such as Polylactic Acid (PLA), Polyhydroxyalkanoates (PHA), Thermoplastic Starch (TPS), Bio-urethanes (BUR), and so on, and debates over which of these materials to name as bioplastics. In a way, these tensions are making the field (Misa, 1992), so I do not favour narrowing my focus to only one type of bioplastics. Moreover, the (hi)story of bioplastics that spans for only about a decade and the lack of historical accounts and systematic inquiry into the field do not allow me to prioritize a certain type, a company or producer that has made the breakthrough.

Interestingly, although the material category 'bioplastics' emerged only after 20052006 (Tonuk, 2016a), the materials today categorized as bioplastics have existed for about a century. As taxonomic and cultural studies on plastics show, the first ever plastics produced at the end of the 19th century were what today would be called bioplastics, in that they were biobased - Celluloid, one of the first plastics, was made of cellulose, 
which is derived from plants (Katz, 1978; Meikle, 1997; Sparke, 1994). In time, plastics made of petroleum became more relevant to a fast-growing industry since petroleum was regarded as an infinite source, and the marvel material Bakelite - a petroleum based plastic, and the first ever commercially successful plastic - was valued as it overcame the imperfections of nature with its shiny smooth qualities and as it simply resisted decay and obsolescence (Meikle, 1997). Moreover, petroleum based plastics were valued as they did not 'take from' mother earth.

However, currently, within raised concerns about broader issues to do with climate change, environmentally harmful aspects of plastic waste and carbon emissions have come to expert and public attention. This context of changing perceptions of sustainability - from using petroleum to natural sources - diminishing petroleum sources, and the growing emphasis on plastic waste, has arguably created a context for new environmentally friendly valuations of plastics. As such, biobased-ness, which is 'taking from' nature, and biodegradability, which essentially means to 'decay' by not being able to sustain its molecular structure, came to be valued as environmentally friendly attributes.

During their short history of about a decade, bioplastics have established their place as a rapidly growing industry and present a promising field to investors, with a growth rate of 20-25 percent a year, whereas traditional plastics are growing between 4-9 percent per year (Thielen, 2012). Today bioplastics present a growing industry with high hopes and investment from various industries, governmental bodies, and enthusiasts:

We are in the infancy of bioplastics. But I am sure that they will survive and that they will not only survive for themselves, but they will survive traditional plastics, and they will become traditional plastics in the future. ${ }^{1}$

This ambiguity, recent history, rapid growth and the changing values give the field an opportunistic and fluid character. This apparent challenge is in fact useful for the purposes of this study and enables me to explore and pursue the relationships in real-time. The relations that make up the field are not stabilized, both in terms of the 'larger whole' using Molotch's (2003) terms but also in terms of material-product combinations. Briefly, the different sourcing, disposal and regulation regarding bioplastics construct a different set of relationships, dynamics and practices than that of the contemporary plastics industry. For example, biobased bioplastics radically challenge the relationships between the oil industry, the petrochemical industry and governments regarding their economic development plans regarding oil dependency. As just one example, the US Department of Agriculture (USDA) and the US Federal Trade Commission have initiated the 'BioPreferred Program', where government organizations are obliged to buy biobased products. Biodegradability represents yet other interests in the field. The different end-of-life options offered by biodegradable plastics relate to different governmental and commercial waste management practices and interests, such as incineration, composting, and recycling organizations and infrastructures. The emerging and varied material culture of bioplastics implies new organizations of people, practices and things, where most of these social and technical relations are emergent and not stabilized.

Also, the material-product relations are not set. Different types of bioplastics are made into a range of different products, some of which turn out to be successful market 
applications and some of which are not so successful, although a lot of investment and time is spent on them. ${ }^{2}$ Clearly 'bio' and the new ways of conceptualizing nature are an important context for bioplastic products; as Max Liboiron (2016) shows in her account, material characteristics are central to their agency. However, a lot of different types of products from consumer products, such as mobile phone casing and automobiles, to food packaging and specialist applications, such as bone scaffolds or support material for 3D-printing are made of bioplastics. For example, cigarette filter tows are made of bioplastics, which do not relate to the upfront bio-qualities of the material, where apparently different qualities are in play. Similarly, in her study of qualities of PET, Hawkins (2013) shows that something extremely durable like PET, which lasts hundreds of years intact in nature, came to be qualified as disposable in certain products, such as bottles. The fact that the significance of materials and their qualities are shaped or remade in relation to products prompts me to consider that the specificity of a material is about its materialproduct combinations.

\section{Production and producers of bioplastics}

Miller (2005) advises in his methodology that we should attend to the principle of mutual constitution between objects and individuals. Accordingly, I do not study the materials and material-product combinations, but the practices and relations through which objects and materials are 'mutually constitutive'. To be able to capture 'the material' and its relationships to 'products' in its becoming, I focus on industrial - mass - production of bioplastics and their manufacturing into products as these are processes through which materials are realized in daily lives. However, this is not to suggest that industrial production is the only site of the making of a material and where its significance is enacted, rather, the aim is to attend to the processes where the material-product relationship is envisioned and brought about, in a fluid and emergent field.

Production of biobased bioplastics starts with the production of certain biomass in plantation sites. If the bioplastic is not biobased, the source is petroleum. These 'raw' materials, either biomass or petroleum, are turned into bioplastics granules - small plastic beads. Like any other plastic granule, bioplastic granules are supplied to, stored and melt-processed at various manufacturers. I use the term 'bioplastics producers' for groups involved with this industrial production; however, I do not intend to suggest a separation between the production and consumption spheres, but rather implicate the 'physical' makers of bioplastics. And these physical makers, just as any user of bioplastics, are situated within the material and social organization of bioplastics, more specifically, in this case, within the material and social organization of production processes and the different groups and their interests involved.

Within this overall picture of production, 'substituting' seems to be one of the main routes through which new materials are realized in the market as products. Manzini (1986: 60) in his book The Material of Invention, which explores many aspects of materials in daily lives and in interaction with individual users, states that the first phase of 'the introduction of a new material into a field of applications' is 'substitution and imitation'. My empirical data also reveal that substitution is a route by which bioplastics producers introduce bioplastics. Paul Mines, the CEO of Biome - a bioplastics producer 
- explains that bioplastics are usually realized through replacing another material in an existing product:

I am trying to think of an exception where someone had come to us and wanted to launch a completely new product, but I can't think of one. Most of them already have a product running in oil-based plastic and then want to change it.

However, I want to conceptualize 'substituting' not only as a technical process comprised of simply replacing one material with another, but also a methodological tool that opens a window into the social and technical relations that inform the making of bioplastics. Here, Callon et al.'s (2002) sociology of markets, informed by science and technology studies opens up to me a perspective from which to look at materials within their networks of relations, where different actors take part in the making of materials. Substitution happens in different instances of bioplastics' life from production to disposal, where different actors, with different interests, come into relation with bioplastics. In these different worlds, bioplastics have to be positioned by comparing them with the previous and alternative materials and social and technical arrangements, so as to define their value (Callon et al., 2002). Callon et al. conceptualize this as 'qualification trials', the 'processes through which qualities are attributed, stabilised, objectified and arranged' (p. 199). Similarly, substituting is part of the making and defining of bioplastics in terms of the dynamic of establishing and valuing materials in and through complex relations between different groups - human and non-human - within the specificity of the production chain. As such, substituting is a generative process, in which some aspects of bioplastics become relevant, valued, made visible and reproduced, and bioplastics are positioned in relation to other materials, and in relation to specific products, and so new values and materializations are produced and reproduced.

Thus, following bioplastics into different instances of substituting offers methodological advantages. It allows me to enter the field composed of fluid relations, for which neither a beginning nor an end can be determined by enabling me to fix the relations temporarily, for a particular instance of substitution, as well as allowing me to bracket the instances of complex and interconnected production processes, and temporarily stabilizing relations, comparisons and values. Following bioplastics into different instances of substituting allows me to explore the materials that went before bioplastics and social and technical arrangements in which bioplastic materials are situated, and the co-existing materials or other products. Moreover, exploring substituting lets me investigate the interface between materials and products, in that I can see materials as separate yet interrelated with products, and consider their making into products and the qualities and terms of evaluation that become relevant in specific arrangements of bioplastics, products, and other materials.

Within the scope of this article I present information derived through semi-structured interviews with representatives of bioplastics producers. ${ }^{3}$ As my interviews revealed, material producers often monitor and guide the whole process of production of materials up to the realization of the product. This close involvement may be inherent to a new industry in which new relations between actors are being formed, and in which material producers are keen to make sure their materials work well in practice, and successfully substitute for those materials that they replace. Without this involvement, as my 
respondents explained, product manufacturers are hesitant to feed a new and unknown material into the production equipment in which they have invested. Speaking with bioplastics producers therefore provided me with a broad view of the processes involved.

Moreover, my sample includes a fruitful variety of bioplastics producers in terms of substitution routes they take; they produce very different materials in different scales that go through different production processes and are made into very different products, so their route into bioplastics industry and groups involved are multiple. Thus, the relations they are situated in are indicative of the processes, dynamics, relations and human and non-human arrangements in and through which specific qualities of bioplastics are elaborated by differently interested actors.

The representatives I spoke to are authorities in their companies, as well as being influential members themselves through their key positions in the industry and related organizations. I conducted interviews with Marc Verbruggen, the President and CEO of NatureWorks, USA, the largest PLA producer worldwide with a 50 percent market share; Paul Mines, the CEO of Biome, UK - a new and small scale bioplastics producers of speciality bioplastics - who is a member of the Management Board of Lignocellulosic Biorefinery Network in the UK; Andy Sweetman, former Chairman of European Bioplastics Association and the Global Marketing Director of Innovia, UK, which is one of the oldest bioplastics producers in the field; Francesco Degli Innocenti, the Director of the Ecology of Products and Environmental Communication of Novamont, Italy, a pioneering bioplastics producer from 1980s; and Sasha Herriot, the Marketing Representative of Clarifoil, UK, a veteran bioplastics producer from the 1930s.

I take the perspective of bioplastics producers and what they make 'visible' and relevant for me. Within the conceptualization explained above, based on the ideas of Callon et al. (2002), I see what the actors make visible (for me) as a strategy that different actors use to negotiate the value of materials; these qualities are charged with the different interests of differently related actors, and reveal the stakes around bioplastics - the important qualities, issues and discussions that inform the field of bioplastics.

The quote below from Marc Verbruggen, the CEO of NatureWorks, the largest bioplastic producer globally, shows how NatureWorks sees 'making visible' as an integral process to how their company works, a strategy that is refined through long-lasting relations in the field:

... what we learned over time is how to fine-tune your message [meaning what to make visible and how], how to fine-tune your value sale, depending on the application, and depending on the region of the world. ${ }^{4}$

Verbruggen's explanation shows how NatureWorks adjust their message to address particular values of certain sectors and regions. They make different qualities visible to different actors, in different arrangements, so as to negotiate - to fix and to challenge the identities and qualities of materials, and to position themselves in relation to other materials. As Verbruggen explains further:

If you make PLA for example in shrink film, or PLA for other film applications, the gloss and the brightness of colours if you print on that film in PLA is very very good. So, for that particular 
application of course, you've got to talk a lot about these particular attributes. Now, if you have a very different application, like for example for a compostable item, probably it is not that important that you have great printing qualities, great gloss, so therefore you are not going to emphasize that particular part. So, from a marketing point of view, what you have to get good at, what you have to develop is which attributes are the most important for particular markets. And then of course make sure that you target these attributes to the right audience and to the right consumers and customers.

This suggests that bioplastics producers manipulate the position of materials by making certain qualities upfront for certain audiences and silencing others that might obstruct or contrast with the symbolic and material associations of the material. For example, as the quote suggests, consumers and brands do not expect bright colours and good printability from compostable products, and therefore these qualities are not elaborated in these particular cases. As such, making visible figures as a strategy through which bioplastics makers negotiate qualities of bioplastics.

\section{Making a new material: Experimenting with limits, modifications and blends}

Following the conceptualizations of substitution and making visible, materials, from the start, figure as made in their relations. Andy Sweetman, Global Marketing Director of Innovia, has explained to me the process of making bioplastics with the analogy of baking a cake:

... we are baking a cake, it is like getting all the ingredients and then we process them, cook them, and we actually manufacture the cake. So, it is the same approach in that sense ... we are taking a range of raw materials, and then going through a mixture of chemical and mechanical processes to produce a product (product here stands for bioplastic film materials, which are the product of Innovia).

Sweetman (and other bioplastics producers) explain that in making bioplastics they use certain bioplastics formulations together with certain resins, ${ }^{5}$ meaning they mix some formulations together to come up with or to enhance certain qualities that will prove useful in certain product functions and performance. Innovia, which is one of the first plastics producers globally - founded originally under the name White \& Co Ltd, in 1912, Wigton, UK, producing Cellophane ${ }^{6}$ - produces bioplastics from cellulose. Wood pulp, which is essentially cellulose, is supplied by forestry companies. The bales of wood pulp are dissolved into cellulose and mixed with different resins and formulations to produce different grades of bioplastics, trademarked as NatureFlex by Innovia.

As can be inferred from the above quote, and as will become clearer in the next pages, the ingredients mentioned above are indeed physical and technical components, as well as social and conceptual components, such as ease with sealing, biodegradability, the quality of gloss or the way materials 'feel'. As Bensaude-Vincent and Stengers (1996) argue in their book, A History of Chemistry, materials are embedded with information about the human and non-human environment, where these environments are not external, but are, rather, constitutive of the materials. According to Bensaude-Vincent and 
Stengers, materials do not exist in isolation; on the contrary, even molecular formations hold information about their environment, in that the position of chemistry and the materials it produces are continually redefined by the materiality of the laboratory, institutions that are in relation with chemistry and its products, and meanings assigned to these, test schemes, intellectual property rights and interests of companies.

This is not to deny that materials have a say in what they become, using Bennett's (2010: viii) terms in her political philosophical account of materials: materials have a 'capacity' which enables them 'not only to impede or block the will and designs of humans but also to act as quasi agents or forces with trajectories, propensities, or tendencies of their own'. The way in which materials exert themselves against the will of different actors are expressed by Mark Verbruggen, the CEO of NatureWorks - the largest bioplastics producer to date - as follows:

Some people believe that a product like PLA is somehow magical, that it can be used for anything, but of course there are limits, and these are chemistry limits.

Verbruggen and other representatives of bioplastics producers acknowledge that bioplastics have tendencies of their own. Referring again to Bennett (2010), she criticizes a view of materials as 'passive victims' of external forces that are shaped by those who are involved in their making. According to her, materials are 'active agents' of social lives; 'vibrant' and active in shaping the relations they are involved with that she calls the 'vitality of materials' (p. viii). Bennett takes the agency of materials even further. She uses the term agency in a Latourian sense, and sees matter as an active force shaping the action that it is involved in. She exhausts the object-subject duality and actually reduces them to one and the same thing. Hence, materials, just like humans, are 'a creative materiality with incipient tendencies and propensities, which are variably enacted depending on the other forces, affects, or bodies with which they come into close contact' (p. 56).

My exploration shows that, although there are capacities and tendencies of materials, there are also means, such as adding resins, with which these tendencies can be modified and made more and more informed. Klein (2009: 19) in her account of materials in early modern Europe terms this as manipulation of matter, and there were different ways in which matter was manipulated:

The manipulations of matter in the early modern period were closely connected to the social order as well as to commodification and wealth, as in the making of luxury fabrics or the marketing of new material medica. They might also exemplify religious debates and political goals of various kinds.

My analysis of the production processes reveals that the tension between the 'capacities' of bioplastics, and the extent to which they can be modified, is a challenge to production of bioplastics, which is sometimes frustrating, sometimes surprising and sometimes in ways that create tensions among various actors involved. Moreover, as Max Liboiron (2016: 91) observes, 'matter does not always interact with other matter in predictable ways, particularly for plastics and their associated monomers and plasticizers.' Likewise, as a material recently in the making, the extent of possible modification cannot be known before it is tried. 
This arguably gives an 'experimental' character to the making of materials: it is not always the outcome of a planned corporate research and development process. The explanations of the material processors underline this experimental and manifold process. Again, quoting from Andy Sweetman about the cellulose film production at Innovia:

So sometimes you will have to try it, and you just have to accept a degree of failures, maybe one in three, of our trials will fail technically ... Very often, probably too often, we might try a standard film, and it may fail technically, because it isn't quite strong enough or it hasn't sealed quite enough, you can't, you don't always know enough, about whether it will work.

Next to being modified (to match certain product conventions and requirements) a lot of the materials are combined in blends. Andy Sweetman explains that many products are actually more complex than they appear to be:

One of the things that people don't realize is that a lot of the packs, which are on the shelves in the supermarkets, are not just one film; they are a laminate of different layers.

To give an example, as Andy Sweetman explains, a coffee pack for ground coffee consists of different materials:

Conventionally for a coffee pack, it is a polyester film, then aluminium foil, and then polyethylene. So, three different materials to marry the different properties. The polyester gives the print-work, the aluminium gives the barrier, and the polyethylene gives the sealability. In this case we have replaced the polyester with the clear NatureFlex [the trademarked bioplastic material of Innovia], the aluminium foil was replaced by metalized NatureFlex, and the polyethylene was replaced by Mater-Bi [the trademarked bioplastics of Novamont].

This quote demonstrates that each material plays a different role: as a barrier to keep the coffee fresh; print-ability for product conventions, such as packaging with printed information on it; and seal-ability, to fit the production route - after being filled, the pack has to be sealed on a particular type of machine. In the case described, materials are blended to meet specific requirements for the product, the production process and further processes, e.g. filling. Each material plays a different role to meet specific product-related requirements, as well as fitting into the existing social and material organization.

Explorations so far elaborated on the analogy of 'baking a cake' by referring to studies on materials and data gathered from my field, where ingredients of the 'cake' appear to be both social and technical or material, and these ingredients are blended, materials are modified in processes of experimentation.

\section{Specialization: A product-oriented route}

My analysis of the production processes reveals that modification is oriented towards product function and performance requirements, conventions and acquired knowledge as to how a product should 'feel' or interact with its users, production route and further processes. In their production, bioplastics are developed and accomplished always in relation to a 'product' application, and its production route. In this way, bioplastics are 
always judged and positioned in terms of the symbolic, material and technical qualities of the product. This link is the most salient in the case of material producers that supply to only one sector, such as Innovia, which predominantly supplies to the packaging sector. Innovia's bioplastic - NatureFlex - comes out in a film format. It is either already the packaging product, or is sent to successive processors to be manufactured - cut and printed - into a more elaborate type of packaging.

Nevertheless, as my interviews revealed, other bioplastics producers, who do not supply to only one fixed sector, also focus on specific products and production routes. For example, NatureWorks always envisages its bioplastic material in a product. As one of the first bioplastics producers in the field and currently the largest, when asked about the process through which bioplastics came to be, Marc Verbruggen, the CEO of NatureWorks, replied:

If I go back in time, and let's use 2003 as the starting point, because 2003 is when we actually built the large plant in Nebraska and therefore we had a lot of product to sell, what you see there is that originally, I mean one of the first things you need to do is try to find the appropriate application for your product [here product stands for the product of NatureWorks, which is actually the bioplastic material].

Verbruggen explains that the first step in making and developing their materials is to find an 'appropriate application'. The discourse of Marc Verbruggen and other bioplastics producers, in which bioplastics are referred to as 'the product' and what others would recognize as the end-product as 'the application' is suggestive on its own. According to the bioplastics producers, end-products are 'applications' of materials. They are still materials, but are 'applied' to different usages. As such, rather than two separate units as 'material' and 'product', products are materials put to use for a cause, hence the relationship between materials and products appears as that of 'application'.

Moreover, the organizational and functional units at NatureWorks asserts that their PLA type bioplastics - Ingeo - is systematically developed towards products. As Verbruggen explains, NatureWorks organizes research and development of Ingeo with reference to specific sectors and sites of application:

We are organized in market segments. And I think we have six or seven global market segments. And the reason why we are organized that way is that it is very specific knowledge about the certain market segment. So we have experts for example in film, yeah? And that expertise is very different than the expertise you need in durable goods or in food service or than you need in nonwovens ... that's why we have specialists, application specialists, not PLA specialists, for a lot of different applications, and they can then test, judge whether or not that particular application makes sense.

In this case, market segments refer to specific product areas such as film, durable goods, and food service. Within this segmentation, Verbruggen stresses 'the application specialists' as opposed to 'PLA material specialists'. Similarly, in 2009, NatureWorks opened an 'applications lab', investing \$1 million. This lab is intended for 'developing and testing compounds on commercial machines, moving Ingeo natural plastic into new product areas, demonstrating Ingeo processing characteristics to converters and working side by side with brand owners to test their product concepts' (NatureWorks, 2009). Setting up an 
applications lab, where materials are internally tested in relation to product and product production routes, shows that materials are developed to become certain products and are tested in various ways in comparison to existing material-product arrangements.

My own work following this making more in detail of material-product specificity found that qualities of bioplastics are made in relation to products, and that their value is constructed in relation to (a) anticipated forms of use and performance, related to specific end-uses and end-products, (b) qualities of the previous materials that were used to make the same product, (c) social and technical traditions of the production processes associated with these specific product-material combinations, and (d) the further production arrangements that the material will encounter in use, and the conditions and qualities associated with these processes (Tonuk, 2016b).

I want to underline the point that what qualities are attended to has a quite specific, often product-oriented history. I keep observations about the intrinsic tendencies and capacities of molecules in mind, but expand on this by recalling 'the informed materials' idea of Bensaude-Vincent and Stengers (1996). On the one hand, the valuable qualities that a material should possess, if it is to be used in making a particular product, are defined by established conventions of marketing and production. On the other hand, materials are constantly modified to achieve these criteria. This apparent customization towards products enables me to term this modification as 'specialization', where materials become more and more specialized towards certain products or end uses.

For example, as Sweetman explains, in the packaging industry every product has certain customs to which materials try to match:

If you had potato chips in a polyethylene bag, it wouldn't feel right ... consumers sometimes associate how products feel with freshness so they want, they don't want it really, really, loud, it hurts their ears, but ... if the packaging feels the right kind of crispy-ness, they kind of think that the product is right as well.

He explains how the material was specialized until the right type of crispiness, informed by acquired wisdoms as to how a certain product should feel, was achieved for potato chips through user tests.

Bioplastics producers' explanations portray the extent of specialization in that even each brand has its own trademarked material for a certain product or a product part. I refer to Paul Mines' explanation where he talks about the difficulties that the bioplastics industry faces and will have to overcome to succeed in a plastics world:

If you went to Dow, DuPont or BAFS websites, you would see there are thousands and thousands of different plastic types ... there are plastics for Mercedes rear bumpers, for BMW rear bumpers, all with different characteristics ... there are plastics for every possible application, with different properties. But with bioplastics, with each application we have to start again, because we have a range of 20 products not a product range of 2000.

This quotation shows that the plastics industry is extremely specialized, insofar as each car brand has its own bumper material. And bioplastics, which now include a growing range of different types and grades, are following the same route, getting more and more specialized towards products. 


\section{Compromise: Clashing worlds}

My analysis shows that specialization takes hold through 'compromises' - among materials and their active live-ness, other materials, products and production equipment, social and technical organization of production, and various interests of groups involved.

My interviews with bioplastic producers reveal that various interests are embedded into what bioplastics come to be. Andy Sweetman's explanation of their relationships with their customers exemplifies some of the stakes in making bioplastics:

We have got a customer who makes a particular format of pack, ok? And we tried a 30-micron film, so a film with a particular thickness, and it wouldn't run on the machine. So, we tried a much thicker film and it ran beautifully, but because it was so thick, it was really expensive. So, they said 'ok, that price is ok, but it doesn't work, that price is too high but it works.' So, we're now doing test work to maybe develop a particular new thickness film that has the right balancing properties, is cost effective enough but it technically works as well.

Sweetman's explanation reveals material and social organizations that 'inform' bioplastics. First, the materiality of this particular formulation of Ingeo has to work well with the existing materiality and practices developed around plastic films; it has to fit into the existing practices and materiality of production in that this substitute material goes through the same equipment and physically and technically runs in the machinery. Second, as Sweetman clarifies, the thickness of the material mentioned is significant for the food item that is going to be stored in this packaging: if it is too thin then sharp grains contained tear the packaging; for example, packaging a kilo of rice is different to that of a kilo of lentils. Third, economic expectations of the investor or the brand have to be satisfied. So, the functional and economic dynamics get resolved in a certain formulation of NatureFlex.

This quotation also shows that material customization involves a compromise among the different actors - human and non-human - involved. In this case, the compromise was about the economic concerns of the brand, the specific requirements of the food item to be packed, and the materiality of manufacturing. I want to give one more example to develop my point on the making of materials as compromise. Paul Mines, from Biome, says that:

[Bioplastics] are not as chemically resistant or heat resistant [as oil based plastics], so probably can adjust and match, but often you have to find exactly the right balance of properties in the bioplastic that allows it to be used in the cycle or application. And that might be temperature stability, might be chemical resistance, it might be colour, it might be light resistance. So, you just have to find that point where the properties work for the application, but the material remains to be compostable within 12 weeks, which is the requirement of the standards. (emphases added)

This quotation hints at negotiations among different actors involved in the making of materials. These actors have different interests. For example, brands often value printability, and want their products to perform well, such as designing packaging to keep food fresh. Processors are more concerned about how well the material performs and about its 
compatibility with their existing equipment. Bioplastics producers highlight different qualities for different audiences. These actors achieve a compromise between these diverse concerns, and materials are qualified in and through these various arrangements.

\section{Materials as temporally specific phenomena and their relationships to products}

this article explored the making of bioplastics and elaborated more in detail on the processes of experimentation and modification. I showed that modification of materials is an ongoing process of specialization organized around the particularity of anticipated product use, performance and production. This specialization is the outcome of a process of compromise between human and non-human actors involved. Since bioplastics are made into a variety of products, their identities are multiple, each specialized in different directions through different social and material organizations. Moreover, these specializations are likely to change and multiply in response to new qualities, new materials, new products and practices. This means that the qualities elaborated in one time-frame are likely to change as new properties gain value. Barry (2005) in his account of the ways in which human and non-human environments get involved in the making of pharmaceutical materials, conceptualizes this temporality by stating that a molecule is an 'historic route'. I extend on his ideas in my analysis and show that this route appears to be product specific; with each materialization within the specificity of material-product combinations, for a brief instance relations seem stabilized, where new valuations and materializations are produced and reproduced. These relations and valuations are reproduced and reworked with each material-product couple and feed back into what materials (and products) become. Therefore, I conceptualize materials, in general, as temporally specific phenomena. This conceptualization and ideas about specialization and compromise are applicable to all materials, and making materials is a constant remaking, in mutual constitution with the arrangements through which materials come to be as they are.

Moreover, this study called attention to a new set of relationships, more specifically that of material-product relationships, and showed what it means for the study of bioplastics. This relationship is first set out with initial thoughts derived from the literature on materials, where materials and products are seen to be in tension or just the opposite, as inseparable. Then, I used Shove et al.'s (2007) conceptualization of co-constitution and expanded on their ideas by unfolding the relationships involved with bioplastics production. At some points, in the eyes of bioplastics producers, products appeared as applications of materials. However, products are involved in separate networks from those of bioplastics and therefore feed back into materials in distinct ways. My study showed that materials and products are both separate but also intricately interrelated. In this way, products make materials as well as being made out of them and they keep remaking each other in various ways. As such, in studying materials (and objects) although sometimes it is useful to take the material-product combination as the unit of analysis and as inseparable, at times there is value in exploring the material devoid of object form, in their own right, and exploring the ways in which materials and products feed back into each other. Moreover, I offered a conceptualization of substitution as a generative process, as a way into unfolding the relationships involved. 
Within this material culture approach, by defining the specificity of materials as their material-product combinations, I was able to open up new relations that are otherwise not attended. Seeing materials as technologies or drivers of social change misses their specificity and the relations shaped around them. In this sense, what Bijker (1995: 13) observes of technological innovation as random modifications, where in Bijker's account of the social and technological change of bicycles, Bakelite and light bulbs, that is summarized as 'a process of trial and error, as a cumulative result of small and mostly random modifications' as opposed to having a 'goal-oriented' or intrinsic character, I realize that making of materials follows quite a productoriented route.

This also opens the way for further studies that add to studies of materials in the generic - the category as a whole and its identity - and explore their making in the specific, where material-product relationships can be detailed and show us more specific ways in which materials and products make each other. It is also important to note that the account here gives an insight into a particular moment in the story of the emerging field of bioplastics, and from a certain perspective. There are clearly other sites in which values and categories of bioplastics are made, in their relations to different users from those of the companies mentioned, and social and material organizations such as standardization infrastructures, market space and so on.

\section{Acknowledgements}

I would like to thank my supervisors Professor Elizabeth Shove and Professor Lucy Suchman, two inspiring academicians, for their valuable discussions and guidance on my $\mathrm{PhD}$ dissertation on which this study is based. Also, I would like to thank the representatives of bioplastics producers for sharing with me their insight and knowledge on the field. I would also like to thank the two anonymous reviewers for their valuable suggestions on an earlier version of this article.

\section{Funding}

This research received no specific grant from any funding agency in the public, commercial, or not-for-profit sectors and there is no conflict of interest.

\section{Notes}

1. As Michael Thielen, the editor of Bioplastics Magazine and the author of Bioplastics: Basics, Applications, Markets, expressed in my interview on 10 October 2013.

2. As an example, Marc Verbruggen, the CEO of NatureWorks, explains that a lot of time and money were invested in realizing water bottles made of PLA between 2004-2008. Also a scan of Bioplastics Magazine shows that there were special sections of the magazine on bottles and bottle production as well as PLA bottle conferences organized in 2004 and 2008. However, although PLA bottles are commercialized in some niche markets, they did not make the breakthrough expected of them.

3. Important to note here is that this article rests on a broader study on how bioplastics come to be (Tonuk, 2016a), where the bioplastics field is explored more in depth, through interviews with representatives of various makers of bioplastics and through secondary sources, such as websites, factsheets and Bioplastics Magazine, the largest international trade magazine devoted to bioplastics.

4. Quotation derived from my interview with Marc Verbruggen on 28 May 2014. 
5. Resins (produced by bioplastics producers or separate resin producers) are different formulations that are added to the molten granules in production processes to alter or enhance certain qualities, such as heat resistance.

6. Information derived from http://www.innoviafilms.com/innovation-centre/Innovation-Timeline. aspx on 10 December 2016.

\section{References}

Akrich M (1992) The de-scription of technical objects. In Bijker W, Law J (eds) Shaping Technology/Building Society: Studies in Sociotechnical Change. Cambridge, MA: MIT Press, 205-224.

Banerjee M and Miller D (2003) The Sari. Oxford: Berg.

Barry A (2005) Pharmaceutical matters: The invention of informed materials. Theory, Culture \& Society 22(1): 51-69.

Bennett J (2010) Vibrant Matter: A Political Ecology of Things. Durham, NC: Duke University Press.

Bensaude-Vincent B and Stengers I (1996) A History of Chemistry. Cambridge, MA: Harvard University Press.

Bijker W (1995) Of Bicycles, Bakelites, and Bulbs: Toward a Theory of Sociotechnical Change. Cambridge, MA: MIT Press.

Callon M, Méadel C and Rabeharisoa V (2002) The economy of qualities. Economy and Society 31(2): 194-217.

Handley S (1999) Nylon: The Story of a Fashion Revolution. Baltimore, MD: Johns Hopkins University Press.

Hawkins G (2013) Made to be wasted: PET and topologies of disposability. In Gabrys J et al. (eds) Accumulation: The Material Politics of Plastic. New York: Routledge, 49-67.

Ingold T (2007) Materials against materiality. Archaeological Dialogues 14(1): 1-16.

Katz S (1978) Plastics: Design and Materials. London: Studio Vista.

Klein U (2009) 'Introduction: Why materials?' and 'Blending technical innovation and learned natural knowledge: The making of ethers'. In: Klein U, Spary E (eds) Materials and Expertise in Early Modern Europe: Between Market and Laboratory. Chicago: University of Chicago Press, 1-23, 123-157.

Küchler S (2011) Materials and design. In: Clarke A (ed.) Design Anthropology: Object Culture in the 21st Century. New York: Springer, 124-135.

Küchler S (2015) Materials: The story of use. In: Drazin A, Küchler S (eds) The Social Life of Materials. London: Bloomsbury Press, 1-27.

Liboiron M (2016) Redefining pollution and action: The matter of plastics. Journal of Material Culture 2(1):87-110.

Manzini E (1986) The Material of Invention, trans. A Shugaar. Cambridge, MA: MIT Press.

Meikle J (1997) American Plastic: A Cultural History. New Brunswick, NJ: Rutgers University Press.

Miller D (ed.) (2005) Materiality. Durham, NC: Duke University Press.

Miller D (2007) Stone Age or Plastic Age? Archaeological Dialogues 14(1): 23-27.

Misa T (1995) A Nation of Steel: The Making of Modern America, 1865-1925. Baltimore, MD: Johns Hopkins University Press.

Misa T (1992) Controversy and Closure in Technological Change: Constructing 'Steel'. In Bijker W E, Law J (eds) Shaping Technollogy/Building Society: Studies in sociotechnical change. Cambridge, MA: MIT Press, 109-139. 
Molotch H (2003) Where Stuff Comes From: How Toasters, Toilets, Cars, Computers, and Many Others Things Come to Be as They Are. New York: Routledge.

NatureWorks LLC (22 April 2009). NatureWorks Opens State-of-the-Art Applications Lab. Press release available at: http://www.natureworksllc.com/News-and-Events/Press-Releases/2009/04 22-09-Applications\%20Lab (accessed 2 March 2015).

Orland B (2009) Enlightened milk: Reshaping a bodily substance into a chemical object. In: Klein U, Spary E (eds) Materials and Expertise in Early Modern Europe: Between Market and Laboratory. Chicago: University of Chicago Press, 163-197.

Pinch T and Bijker W (1984) The social construction of facts and artefacts: Or how the sociology of science and the sociology of technology might benefit each other. Social Studies of Science 14(3): 399-441.

Schatzberg E (2003) Symbolic culture and technological change: The cultural history of aluminum as an industrial material. Enterprise and Society 4(2), 226-271.

Sheller M (2014) Aluminum Dreams: The Making of Light Modernity. Cambridge, MA: MIT Press.

Shove E et al. (2007) The Design of Everyday Life. Oxford: Berg.

Sparke P (1994) The Plastics Age: From Bakelite to Beanbags and Beyond. Woodstock, NY: Overlook Press.

Thielen M (2012) Bioplastics: Basics Applications Markets. Mönchengladbach: Polymedia.

Tilley C (2007) Materiality in materials. Archaeological Dialogues 14(1): 16-20.

Tonuk D (2016a) Making Bioplastics: An investigation of material-product relationships. $\mathrm{PhD}$ dissertation, Lancaster University.

Tonuk D (2016b) Making materials: The case of elaborating qualities of bioplastics. Design Issues 32(4): 64-75.

\section{Author biography}

Damla Tonuk is a lecturer of design. After completing her training as a product designer, she did her PhD in Sociology focusing on bioplastics and material-product relationships. She is interested in the study of the make-up of the world; materials of design and designed objects - artefacts. Her scholarly interest into things and their substance lies among design, material culture and STS disciplines. Currently, she pursues her scholarly and designerly interests. 